\title{
A Comparative Study of Lateral Load Analysis Considering Two BNBC Codes Using ETABS Software
}

\author{
Faruque Abdullah ${ }^{1}$, Zahidul Islam ${ }^{2, *}$, Mohammad Abu Turab Asif ${ }^{2}$, Sumon Ali $^{2}$ \\ ${ }^{1}$ Department of Building Engineering \& Construction Management, Rajshahi University of Engineering \& Technology, Rajshahi, \\ Bangladesh \\ ${ }^{2}$ Department of Civil Engineering, Rajshahi University of Engineering \& Technology, Rajshahi, Bangladesh
}

\section{Email address:}

abdullah@becm.ruet.ac.bd (F. Abdullah), zahid@ce.ruet.ac.bd (Z. Islam), asifabuturab00@gmail.com (M. A. T. Asif),

smnali112@gmail.com (S. Ali)

*Corresponding author

\section{To cite this article:}

Faruque Abdullah, Zahidul Islam, Mohammad Abu Turab Asif, Sumon Ali. A Comparative Study of Lateral Load Analysis Considering Two Bnbc Codes Using Etabs Software. American Journal of Civil Engineering. Vol. 9, No. 4, 2021, pp. 118-126.

doi: $10.11648 /$ j.ajce. 20210904.13

Received: July 28, 2021; Accepted: August 7, 2021; Published: August 18, 2021

\begin{abstract}
The Bangladesh National Building Code (BNBC) specifies and regulates the general specifications for structural, architecture and design parameters in Bangladesh. In the last three decades, Civil Engineering techniques, knowledge and materials as well as design parameters have been modified as per requirement. As a consequence, BNBC 2010 was written to reflect the transition. In this study, a systematic and parametric structural analysis of a ten-story residential building was analyzed (ETABS 16.0.2 software) by using BNBC 1993 and BNBC 2020 for four different locations (Patuakhali, Chandpur, Rangpur and Moulovibazar) suited in several zones to demonstrate how lateral load affects structural analysis and design of high rise infrastructure. The decision making parameters for structural analysis and design are tremor and wind forces, story drift, wind and seismic shear, moment of unique beams and columns, and base shear for seismic forces according to BNBC 2020 vary significantly compared to BNBC 1993. In this study, the earthquake load varies from $7.42 \%$ to $59.78 \%$, while wind force ranges from $19.16 \%$ to $36.14 \%$ in the $\mathrm{x}$-direction and $49.51 \%$ to $63.78 \%$ for $y$-direction, and story drift for earthquake load ranges from $47.96 \%$ to $51.27 \%$ and for wind load ranges from $29.89 \%$ to $34.45 \%$. The comparison of the aforesaid design parameters is depicted graphically, and relevant tables are presented in this research article. In comparison to BNBC 1993, the requirements of BNBC 2020 usually result in a less cost-effective design with a higher safety margin.
\end{abstract}

Keywords: ETABS, Manual Calculations, BNBC, Shear Force, Bending Moment

\section{Introduction}

The reinforced concrete structure (RC), susceptible to seismic excitation, should be suitable for strength, ductility, and stiffness to meet earthquake-resistant design criteria. [1] The arrangement of the fundamental building elements for rigidity and durability can regulate the reaction behavior of laterally loaded structures, and the damage recorded in earthquake structures was primarily due to their erroneous placement. [2, 3] Considering the increasing population, as well as lack of horizontal expansion, is not a reasonable solution. When houses and apartments are designed there are various structural issues occur such as lateral loads, side moving, stiffness and so on. In general, not only earthquake load affects, but also wind load are prominent for high-rise structures. Hence, different loads and corresponding effects on structures need to be considered for multiple floors. The lateral load impact is extremely important to take earthquake and wind loads into account. [4]

Bangladesh is near the Himalayas, the highest mountain range in the world, and is well inside an active tectonic area and susceptible to significant earthquakes. [5] Lists of some major earthquakes affecting in Bangladesh has been illustrated in Table 1. In an impoverished and heavily populated nation such as ours, the after-effects of an earthquake are harder than in other industrialized countries. [6] Where high-rise structures have been built, several structural issues occur, such as the 
influence of lateral load, lateral moving, and rigidity on structure. In general, not only tremors are significant for highrise buildings, but also wind loads. Therefore, understanding numerous loads and their influence on structures is crucial for a tall building. The influence of lateral loads, such as earthquake and wind loads, is critical to consider. [4] In Bangladesh and other underdeveloped nations, the approach of earthquakes and wind analysis is used in a static analysis because of the lack of modern modeling and computing installations. With the increase in the number of high-rise structures, the code for design, detailing, and construction is increasingly significant. [5]

There are typical issues in the major cities of the world. Rising population concentrations, along with growing land prices and today's climate change policy, resulting in people migrating from the rural to the metropolis leave city managers with no other answer than building up. Development of high rise construction of above 20 stories have therefore emerged essential and are being implemented for the town of Dhaka, in order to satisfy present needs. As the height of the structure rises, a key worry is the lateral motion of the structure owing to wind loads. The collapse of both constructive and non-structural components is associated with severe lateral or inter-story drift. [7] The aim of the guidelines is to provide and improve safety and to maintain a perfect balance among efficiency and security. [8]

Table 1. List of major earthquakes affecting Bangladesh.

\begin{tabular}{lll}
\hline Date & Name of the earthquake & Magnitude (Richter) \\
\hline $10^{\text {th }}$ Jan, 1869 & Cachar Earthquake & 7.5 \\
$14^{\text {th }}$ Jul, 1885 & Bengal Earthquake & 7.0 \\
$10^{\text {th }}$ Jan, 1889 & Jaintia Hills Earthquake & 7.5 \\
$12^{\text {th }}$ Jun, 1897 & Great Indian Earthquake & 8.7 \\
$8^{\text {th }}$ Jul, 1918 & Srimongol Earthquake & 7.6 \\
$3^{\text {rd }}$ Jul, 1930 & Dhubri Earthquake & 7.1 \\
$5^{\text {th }}$ Jan, 1934 & Bihar-Nepal Earthquake & 8.3 \\
\hline
\end{tabular}

The Bangladesh National Building Code (BNBC) was developed in 1993 to offer recommendations for the development and implementation of modern projects that are prone to tremors, will cause a reduction of threat for all buildings. Relative research is interesting to search at the provisions of this code and to see whether adjustments to the latest upgrade code might be made to identify the changes in design and analysis of the various structures. [9] With the development of tall buildings, the global regulations that control infrastructure design, detailing, and construction are updated regularly to reflect new practices. Wind is a dynamic occurrence that changes rapidly and depends on time and speed. It is due to wind movement from a high pressure condition to a low pressure. Bangladesh National Building Code (BNBC) was initially published in 1993, and anticipated wind provision has been modified in BNBC 2017. [10] The previously created Bangladesh Building Code (BNBC) was formally implemented in the year 2006 and was not amended for a long time.

In seismic analysis and design of buildings, attention for the combination of earthquakes and wind force has become extremely important since constructions in the unfavorable circumstances like as tectonically strong zones may inevitably be constructed. A comparative study was performed to observe the important modifications among the BNBC 1993 and the proposed BNBC 2012 in terms of lateral load alone. [9] Significant improvements were made in BNBC 2017 to incorporate knowledge and advances in structural engineering during the last two decades. [11] BNBC 1993 has been modified and published as BNBC 2020 considering the guidelines of other international building standards.

This article tries to compare wind load and earthquake analysis laws given between BNBC 1993 and BNBC 2020. This Benchmarking investigation will offer designers who use BNBC 1993 as their platform for calculating design wind loads with a relationship indicating the percentage changes in design wind load in the new code compared to the old one. Again, this research article will create a pathway to compare with other building codes used all over the world in determining how many factors of safety against wind disaster are imposed considering the economic aspects and population of our country. [12]

\section{Review of Existing Literature}

The BNBC 1993 amendments were first recommended by the Al-Hussaini, T. M. et al. (2012). They performed a detailed investigation into Peak Ground Acceleration (PGA), Spectral Acceleration, a ground categorization system, and an on-site response spectrum. They showed that BNBC 1993 requires a considerable improvement in provisions of design and structural analysis. [5] The following are some references to literature on comparative research of existing codes in Bangladesh and throughout the world.

Sarothi S. Z. et. al., (2019) show primary differences between BNBC 1993 and 2017 to investigate and quantify the changes in the analysis of wind and seismic loads based on structural and economic perspective. They analyzed a multistoried commercial building $(16.5 \mathrm{~m} \mathrm{x} 24 \mathrm{~m})$ situated in Chattogram for both low rise \& high rise building $(8,16$ stories) using finite element analysis. Seismic Base shear is increased in BNBC 2017 w.r.t BNBC 1993 because of variation in zone coefficient $(\mathrm{Z})$, Response modification factor $(\mathrm{R})$, and the introduction of Cs (normalized acceleration response spectrum). On the other hand, BNBC 1993 shows high wind load compared to that in BNBC 2017. Analysis results dictate, the newer code provisions generally results in a relatively less economic design with higher safety margin when compared to the design based on the old code. [13]

Sakib M. S. et. al., (2019) were taken an attempt to undertake a systematic simulation analysis utilizing finite element method (FEM) based on the previous (BNBC 1993) and newly proposed (BNBC 2017) codes to establish a precise comprehension of improvements. They analyzed a multistoried commercial steel building of $16.5 \mathrm{~m} \times 24.0 \mathrm{~m}$ with concentric braced framing system resting on soft to medium stiff clay (8 and 16 story) situated in Chattrogram. 
They observed that the rate of change in base shear reduces with story height owing to both earthquake and wind loads, and that base shear due to wind load is somewhat lower for BNBC 2017 than for BNBC 1993 because of reduced wind pressure coefficient. [11]

Hassan M. M. et. al., (2018) examine the relative assessment of wind load effect in city, obstructed, and unobstructed plain territory type zones as per BNBC 1993 and BNBC 2015. They examined a multistory residential building $(20.0 \mathrm{~m} \times 20.0 \mathrm{~m})$ of $100 \mathrm{~m}$ height for three exposure criteria (i.e. Exposure A, Exposure B, and Exposure C) to explore the effects in structural analysis using the both codes. The rate of change in wind thrust with respect to number of stories seems to be more consistent in BNBC 2015. As per BNBC 2015, exposure A significantly exceeds that of BNBC 1993 by 7-12\%. But Exposure B \& C is much reduced $2-10 \%$ in 2015 compared to BNBC 1993. [10]

Faysal R. M., (2014) studied the comparative study of wind force analysis provided by BNBC 1993 and BNBC 2010. The wind provision recommended in BNBC 2010 is upgraded by the authority taking in consideration of the influence of surrounding structures and building height. As a consequence, wind load in metropolitan regions (Exposure A) is discovered to be significantly greater (7-12\%) compared to BNBC 1993. Meanwhile, wind load computed from this new code for obstructed and unobstructed plain territory region (Exposure $\mathrm{B}$ and $\mathrm{C}$ ) is significantly lower than BNBC 1993. [12]

Imam F. S. et. al, (2014) investigate the comparative evaluation of wind and seismic analysis presented in the BNBC 1993 with the BNBC 2012 suggested. They analyzed a typical multistoried residential building with intermediate moment resisting frame system resting on medium dense soil situated in Dhaka to find the differences in structural analysis between BNBC 2012 and BNBC 1993. The analysis is conducted for variable number of stories (from 2 to 18 ) and it is found that maximum drift occurs almost at the mid height of the building in all cases. Base shear of the residential structure obtained by this new draft code varies significantly and the maximum lateral displacement and inter story drift w.r.t number of stories is less in BNBC 2012 than in BNBC1993 for wind load only. They include that the design of RC building for lateral load in BNBC-2012 is relatively economic than BNBC-1993 as the amount of reinforcement required is less in BNBC-2012 although this is applicable for Dhaka city only. [9]

Bari M. S. and Das T., (2013) illustrate the similarities among specific requirements in BNBC 1993, BNBC 2010, NBC 2005 and ASCE 7-05 regarding tectonic assessment of building codes. This study conveys a seismic safety message for our country at this current location. In this study, BNBC 1993 is shown to have the minimal base shear among the guidelines. Base shear values factorized for BNBC 2010 have improved considerably compared with BNBC 1993 in lower elevated structures $(\mathrm{B} \leq 20 \mathrm{~m})$ over the state across its antecedent. This enhancement of the earthquake safety factor established by the proposed BNBC 2010 code, which recommends greater base shear values, is noteworthy. [6]

Atique F. and Wadud Z., (2001) displays the study of various standards in the design codes (BNBC-93, UBC-91, UBC-97, NBC-83 and Bangladesh outline Code, 1979) for seismic and wind analysis from numerous countries of the world. They analyzed an office building (15.6 m x $15.6 \mathrm{~m})$ located in the United States earthquake Zone 3 (UBC), in Indian Zone V (NBC-83) and Zone 3 (BNBC-93) in Bangladesh similar seismic activity. The analysis was carried out for ten, fifteen, twenty and twenty-five storied building and concluded that developed countries enhanced their seismic safety factor by proposing higher base shear value. In reference to contemporary codes in the current review, the seismic design standards in BNBC-93 are the least conservative in the construction and lead to a significant loss of life and property in a major quake. [16]

\section{Modeling and Analysis}

A typical multistoried (10 story) commercial building of geometrically irregular in plan of 78'-3" x 64'-5" is selected for the proposed study (Figure 1). The building was deemed to rest on the same condition as well as similar structural importance factor for two distinct standards (BNBC 2019 \& BNBC 2020) for both wind and seismic load analysis. In this research work for the wind analysis low-medium-high wind zone has been considered separately and for the earthquake analysis the same procedure has been performed. The proposed structure has been analyzed based on gravity loads which comprises of gravity loads and live loads as well as lateral loads like as wind thrust and seismic load and illustrated in Table 3. As per BNBC 2020 guideline, all the dead loads i.e. self-weight, floor finish, and other super imposed loadings except partition wall were considered in our study.

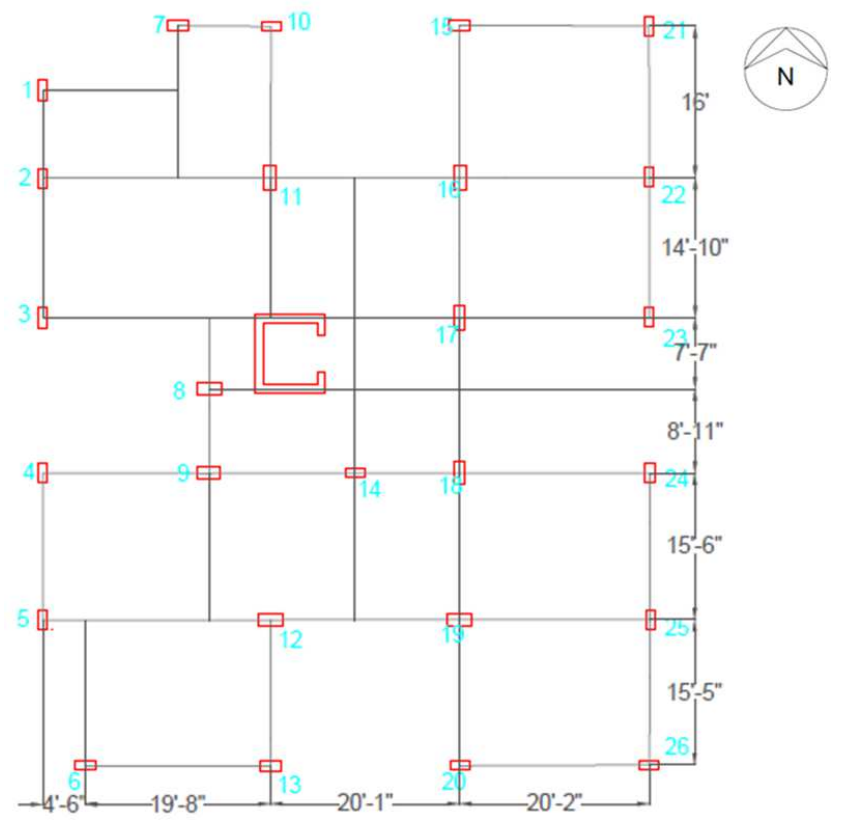

Figure 1. Beam and column Layout. 
The two regulations regard earthquake force as lateral force and calculation procedure is on the basis of a base shear by Equivalent Static Force Method (ESFM). For the structure located in different seismic regions [3 zones according to BNBC 1993 and 4 zones according to BNBC 2020] of Bangladesh, the ESFM was used to determine the seismic lateral forces as the structure is irregular and under 75 meter in accordance with BNBC 1993 and BNBC 2020. Total base shear in a given direction was determined using the equation described in Table 2 . The response modification coefficient $(\mathrm{R})$ for Intermediate Moment Resisting Frame (IMRF) was taken 8 \& 5 according to the code of practice BNBC 1993 and BNBC 2020 respectively. For wind load analysis Surface Area
Method was used in accordance with BNBC 1993 and Analytical Procedure was followed in accordance with BNBC 2020 for the commercial building. The equations used for calculating lateral load for wind thrust has been illustrated in Table 2. The factors are totally changed in the updated code corresponding to the old practice. The structure was modeled three dimensionally in the commercial structural analysis and design software ETABS (Version 19.1.0). The columns were assumed to be fixed at the foundation. Rigid diaphragm action of the slab was simulated. Dead load, live loads and supper imposed live loads (seismic and wind load) were applied as static load on the structure according to Bangladesh National Building Code.

Table 2. Comparison of Design Parameters of BNBC 1993 \& BNBC 2020

\begin{tabular}{|c|c|c|}
\hline Case & BNBC 1993 [14] & BNBC 2020 [15] \\
\hline \multirow{10}{*}{$\begin{array}{l}\text { (a) } \\
\text { Seismic } \\
\text { provisions }\end{array}$} & $\begin{array}{l}\text { 1) The country is divided into three zones (I, II \& III) and } \\
\text { each zone is assigned a coefficient }(0.075,0.15 \& 0.25 \text { for } \\
\text { zone } 1,2 \& 3 \text { respectively). [Table } 6.2 .22 \text { ] }\end{array}$ & $\begin{array}{l}\text { 1) The country is divided into four zones (I, II, III \& IV) and each zone is } \\
\text { assigned a coefficient }(0.12,0.20,0.28 \& 0.36 \text { for zone } 1,2,3 \& 4 \\
\text { respectively). [Table } 6.2 .14 \text { ] }\end{array}$ \\
\hline & $\begin{array}{l}\text { 2) Site classification depends on shear wave velocity and } \\
\text { soil profile depth. Site soils are classified into four types: } \\
S_{1}, S_{2}, S_{3} \& S_{4} \text {. [Table } 6.2 .25 \text { ] }\end{array}$ & $\begin{array}{l}\text { 2) Site classification depends on shear wave velocity and soil profile depth. } \\
\text { Site soils are classified into five types: SA, SB, SC, SD \& SE. [Table } \\
6.2 .25 \text { ] }\end{array}$ \\
\hline & $\begin{array}{l}\text { 3) The building fundamental period, } \mathrm{T}=\mathrm{C}_{\mathrm{t}} \mathrm{h}_{\mathrm{n}}{ }^{3 / 4} \text { where, } \mathrm{h}_{\mathrm{n}} \\
\text { in meter. [Section 2.5.6.2] }\end{array}$ & 3) The building period, $\mathrm{T}=C_{t} h_{n}{ }^{m}$ where, $h_{n}$ in meter. [Section 2.5.7.2] \\
\hline & $\begin{array}{l}\text { 4) Response Modification Coefficient, } R \text { value is } 5,8 \& 12 \text { for } \\
\text { OMRF, IMRF \& SMRF system respectively. [Table 6.2.24] }\end{array}$ & $\begin{array}{l}\text { 4) Response Modification Coefficient, } \mathrm{R} \text { value is } 3,5 \& 8 \text { for ORCMF, } \\
\text { IRCMF \& SRCMF system respectively. [Table } 6.2 .19 \text { ] }\end{array}$ \\
\hline & $\begin{array}{l}\text { 5) Five importance factors } 1.25,1.25,1.0,1.0 \& 1.0 \text { has } \\
\text { been considered. [Table } 6.2 .23 \text { ] }\end{array}$ & $\begin{array}{l}\text { 5) Four importance factors } 1.0,1.0,1.25 \& 1.50 \text { has been considered. [Table } \\
6.2 .17 \text { ] }\end{array}$ \\
\hline & 6) Story drift, $\Delta$, shall be limited as follows: & 6) Story drift, $\Delta$, shall be limited as follows: \\
\hline & a) $\Delta \leq 0.04 \mathrm{~h} / \mathrm{R} \leq 0.005 \mathrm{~h}$ for $\mathrm{T} \leq 0.7 \mathrm{sec}$ & a) $\Delta \leq 0.005 \mathrm{~h}$ for $\mathrm{T}<0.7 \mathrm{sec}$ \\
\hline & b) $\Delta \leq 0.03 \mathrm{~h} / \mathrm{R} \leq 0.004 \mathrm{~h}$ for $\mathrm{T} \geq 0.7 \mathrm{sec}$ & b) $\Delta \leq 0.004 \mathrm{~h}$ for $\mathrm{T} \geq 0.7 \mathrm{sec}$ \\
\hline & c) $\begin{aligned} \Delta \leq 0.0025 \mathrm{~h} \text { for unreinforced masonry structures where, } \mathrm{h} \\
=\text { height of the building [Section } 1.5 .6 .1]\end{aligned}$ & $\begin{array}{l}\text { c) } \Delta \leq 0.0025 \mathrm{~h} \text { for unreinforced masonry structures where, } \mathrm{h}=\text { height of the } \\
\text { building [Section 1.5.6.1] }\end{array}$ \\
\hline & $\begin{array}{l}\text { 7) Design lateral force calculated from ESFM method is } \mathrm{V}= \\
\frac{Z I C}{R} \mathrm{~W} ; \text { Where, } \mathrm{Z}=\text { Seismic zone coefficient, } \mathrm{C}= \\
1.25 \mathrm{~S} / T^{2 / 3} \text { and } \mathrm{W}=\text { the seismic weight of the building. } \\
\text { [Section } 2.5 .6 .1]\end{array}$ & $\begin{array}{l}\text { 7) Design lateral force calculated from ESFM method is } \mathrm{V}=\frac{2}{3} \frac{\mathrm{ZI}}{\mathrm{R}} \mathrm{C}_{\mathrm{s}} \mathrm{W} \text {; } \\
\text { Where, } \mathrm{Z}=\text { Seismic zone coefficient, } \mathrm{C}_{\mathrm{s}}=\text { Normalized acceleration } \\
\text { response spectrum and } \mathrm{W}=\text { the seismic weight of the building (Including } \\
\text { minimum } 25 \% \text { live load and upto } 3 \mathrm{kN} / \mathrm{m}^{2} \text { ). [Section } 2.5 .4 .3 \& 2.5 .7 .1 \text { ] }\end{array}$ \\
\hline \multirow{4}{*}{$\begin{array}{l}\text { (b) Wind } \\
\text { provisions }\end{array}$} & $\begin{array}{l}\text { 8) Fastest-mile wind speeds in } \mathrm{km} / \mathrm{h} \text { corresponding to the } \\
\text { level of } 10 \mathrm{~m} \text { above the ground of terrain of Exposure-B, } \\
\text { specify as basic wind speed. [Section } 2.4 .2 \text { ] }\end{array}$ & $\begin{array}{l}\text { 8) Three-second gust speed at } 10 \mathrm{~m} \text { above the mean ground level in terrain } \\
\text { of Exposure-B, specifies as basic wind speed. [Section 2.1.3] }\end{array}$ \\
\hline & $\begin{array}{l}\text { 9) Sustained wind pressure at height } \mathrm{z}\left(\mathrm{kN} / \mathrm{m}^{2}\right), q_{z}= \\
C_{c} C_{I} C_{z} V_{b}^{2} ; \text { Where, } C_{c}=\text { Velocity to pressure coefficient, } \\
C_{I}=\text { Structural importance coefficient, } C_{z}=\text { Combined } \\
\text { height and exposure coefficient \& } V_{b}=\text { Basic wind speed. } \\
\text { [Section 2.4.6.2] }\end{array}$ & $\begin{array}{l}\text { 9) Velocity pressure at height } \mathrm{z}\left(\mathrm{kN} / \mathrm{m}^{2}\right), q_{z}=0.000613 K_{z} K_{z t} K_{d} V^{2} I \text {; } \\
\text { Where, } K_{z}=\text { Velocity pressure exposure coefficient, } K_{z t}=\text { Topographic } \\
\text { factor, } K_{d}=\text { Wind directionality factor, } \mathrm{V}=\text { Basic wind speed } \& \mathrm{I}= \\
\text { Importance factor. [Section } 2.4 .9 .5 \text { ] }\end{array}$ \\
\hline & $\begin{array}{l}\text { 10) Design wind pressure at height } \mathrm{z}\left(\mathrm{kN} / \mathrm{m}^{2}\right), P_{z}=C_{G} C_{p} q_{z} \text {; } \\
\text { Where, } C_{G}=\text { Gust coefficient \& } C_{p}=\text { Pressure } \\
\text { coefficient. [Section 2.4.6.3] }\end{array}$ & $\begin{array}{l}\text { 10)Design wind pressure at height } \mathrm{z}\left(\mathrm{kN} / \mathrm{m}^{2}\right), P_{z}=\mathrm{G} C_{p} q_{z}-q_{i}\left(\mathrm{G} C_{p i}\right) \\
\text { Where, } \mathrm{G}=\text { Gust effect factor } \& C_{p}=\text { External pressure coefficient, } q_{i}= \\
\text { Velocity pressure for internal pressure determination, } \mathrm{G} C_{p i}=\text { Internal } \\
\text { pressure coefficient. [Section } 2.4 .11 .2 \text { ] }\end{array}$ \\
\hline & $\begin{array}{l}\text { 11) Five importance factors } 1.25,1.25,1.0,1.0,0.80 \text { has } \\
\text { been considered. [Table } 6.2 .9 \text { ] }\end{array}$ & $\begin{array}{l}\text { 11) Four importance factors } 0.87,1.0,1.15 \& 1.15 \text { for wind velocity within } \\
\text { the range } 38-44 \mathrm{~m} / \mathrm{s} \text { and } 0.77,1.0,1.15 \& 1.15 \text { for wind velocity greater } \\
\text { than } 44 \mathrm{~m} / \mathrm{s} \text { has been considered. [Table } 6.2 .9 \text { ] }\end{array}$ \\
\hline
\end{tabular}

Table 3. Dead Load and live load.

\begin{tabular}{lll}
\hline \multirow{2}{*}{ Loads } & Code of practice & \\
\cline { 2 - 3 } & BNBC 1993 & BNBC 2020 \\
\hline \multirow{2}{*}{ Live load } & Floor: $3.00 \mathrm{kN} / \mathrm{m}^{2}$ & Floor: $2.90 \mathrm{kN} / \mathrm{m}^{2}$ \\
Concrete unit weight & Roof: $1.50 \mathrm{kN} / \mathrm{m}^{2}$ & Roof: $1.50 \mathrm{kN} / \mathrm{m}^{2}$ \\
Partition wall loads & $22.80^{*} \mathrm{kN} / \mathrm{m}^{3}$ & $22.80^{*} \mathrm{kN} / \mathrm{m}^{3}$ \\
\hline
\end{tabular}

* For reinforced concrete, add $0.63 \mathrm{kN} / \mathrm{m}^{3}$ for each $1 \%$ by volume of main reinforcement. 


\section{Results and Discussions}

The results of ETABS work, which are the values of earthquake and wind forces, story drift and shear, and moment of various beams and columns, are shown in graphical form after the work has been completed. ETABS works for two distinct codes, BNBC 1993 and BNBC 2020, as well as four distinct zones i.e., Patuakhali, Chandpur, Rangpur, and Moulovibazar. Both codes have some distinguishing features that set them apart from one another. The variations in different parameters illustrated in graphical form in the followings.

\subsection{Comparison of Seismic Load Analysis}

BNBC 2020 provides higher seismic base shear values with respect to story number for four different zones in accordance with compared to BNBC 1993 m (Figure 2). In BNBC 1993, seismic zone coefficient had a lower value of $(0.075,0.15 \& 0.25$ for zone I, II \& III respectively) compared to BNBC 2020 (0.12, 0.20, $0.28 \& 0.36$ for zone I, II, III \& IV respectively). As the zoning map has been updated as well as the value has been increased in BNBC 2020 , there is a positive increase of base share compared to $\mathrm{BNBC}$ 1993. The main difference in base shear is encountered as the Response Modification Coefficient $\mathrm{R}$ value has been changed for different structural system like as Ordinary Moment Resisting Frame (OSRM), Intermediate Moment Resisting Frame (IMRF), Special Moment Resisting

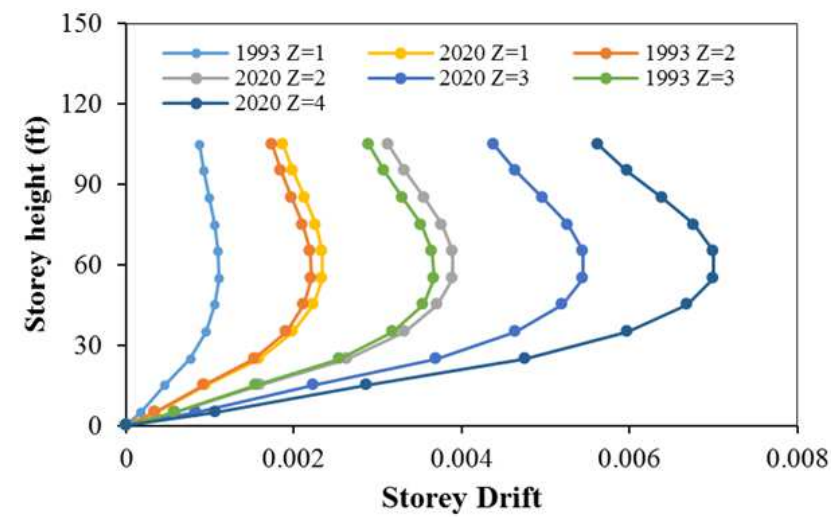

a)
Frame (SMRF), Ordinary Reinforced Concrete Moment Frame (ORCMF), Intermediate Reinforced Concrete Moment Frame (IRCMF) \& Special Reinforced Concrete Moment Frame (SRCMF) as shown in Table 2. The introduction of Cs (normalized acceleration response spectrum) in BNBC 2020 contributes in increasing base shear. Lower values of $\mathrm{R}$ in BNBC 2020 generated a higher spectral acceleration (Sa), which results in increased seismic base shear.

In BNBC 2020, although Design Basis Earthquake (DBE) is considered $2 / 3$ of Maximum Considered Earthquake (MCE), total base shear increases due to addition of $25 \%$ live load as seismic dead weight. There is also a minor change in time period of the building and seismic load also.

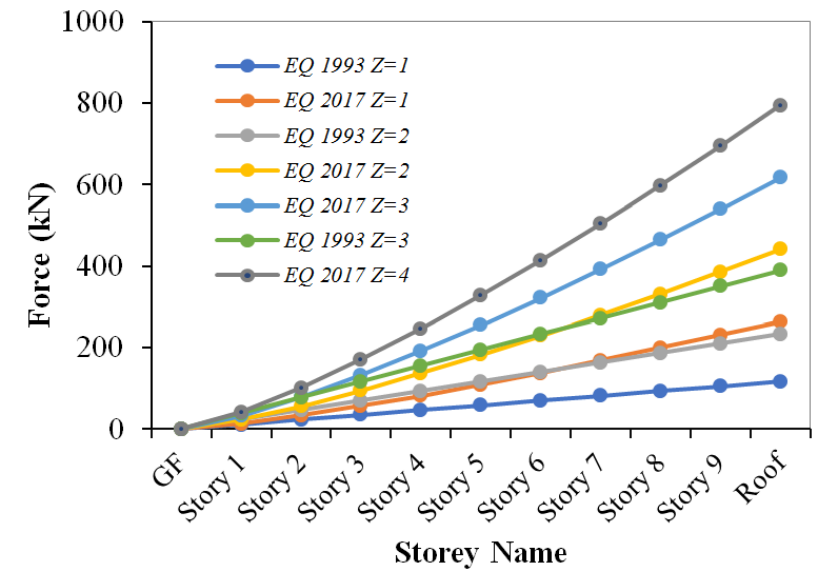

Figure 2. Earthquake force.

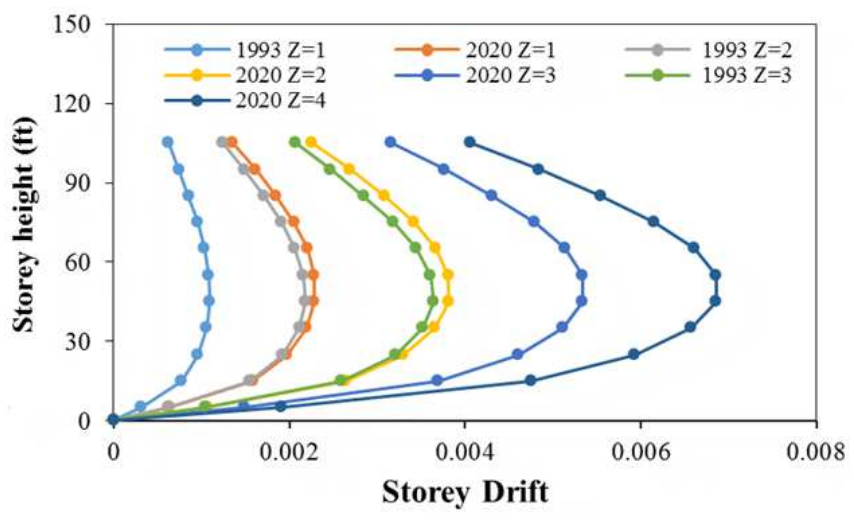

b)

Figure 3. Story drift due to earthquake load; (a) X-direction, (b) $Y$-direction.

In case of story drift a noticeable change has been observed. The story drift is almost twice for the BNBC 2020 compared to the BNBC 1993 for both $\mathrm{x}$ and $\mathrm{y}$ direction in different seismic zones (Patuakhali, Chandpur, Rangpur and Moulovibazar) of Bangladesh. From figure 2 it is evident that the maximum story drift is observed between the third and fifth floors, and its trend rises upward with higher zoning coefficient towards ascending altitude. Drift value is comparatively same for middle story to higher story of a building for lower zone coefficient. Maximum story drift occurs at mid height of a building for any zoning condition.
The rate of change in story drift is almost proportional for all zoning condition although the graph shape changed to a semilunar shape with increase in zone coefficient value. Higher the zoning coefficient higher the maximum drift value. All the values of story drift are within the acceptable limit as provided by the code and illustrated in Table 2 for BNBC 1993 \& BNBC 2020. Permissible limit for story drift is same for both of the codes. The slope of the story drift curve has a good relation with the seismic zone coefficient value. The lower the zone coefficient the stiff the curve is. This behavior is seen upto a certain range and after this range 
the change of the slope is almost constant.

The earthquake force has a direct impact on the shear and moment value of beam which is clear from figure 3. As the earthquake force has been increased, the shear and moment values in different beam has been also increased. B-1 represents the exterior beam and B-2 represents the interior beam. We have chosen six typical exterior beams named as (B1-1 to B-1-6) and four typical interior beam named as (B-1-1 to B-1-4) to find out the impact of earthquake load increase on design values. It is clear from the current study that due to

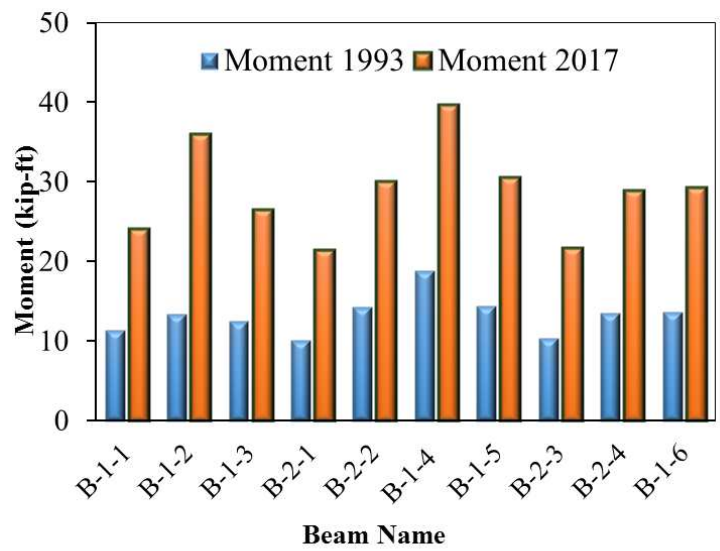

a)

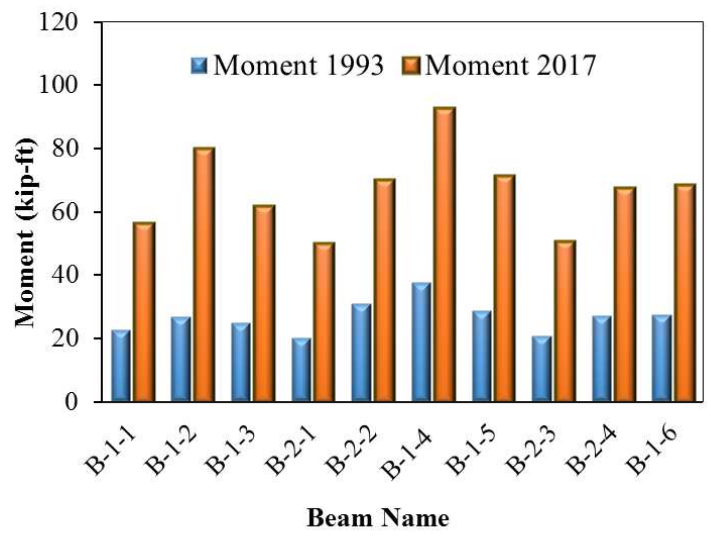

c) increase in earthquake load the increase in shear and moment values is almost twice for BNBC 2020 as compared BNBC 1993. In some cases, the increase in shear and moment is three times for BNBC 2020 and it will cost for an increase in construction cost. For seismic weight now in BNBC 2020 has an extra consideration of live load which is also impact on this increase in values. As the design moment and shear has increased, the corresponding rebar percentage will increase proportionally. Because the rebar percentage has a linear relationship with shear and moment values.

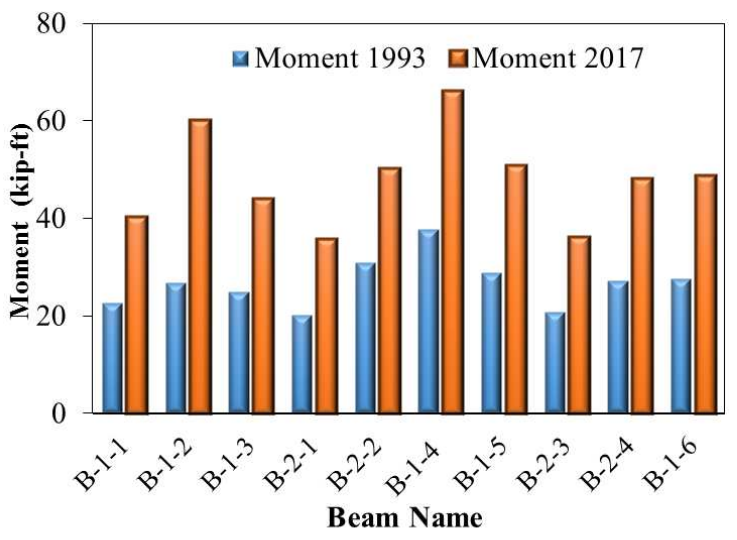

b)

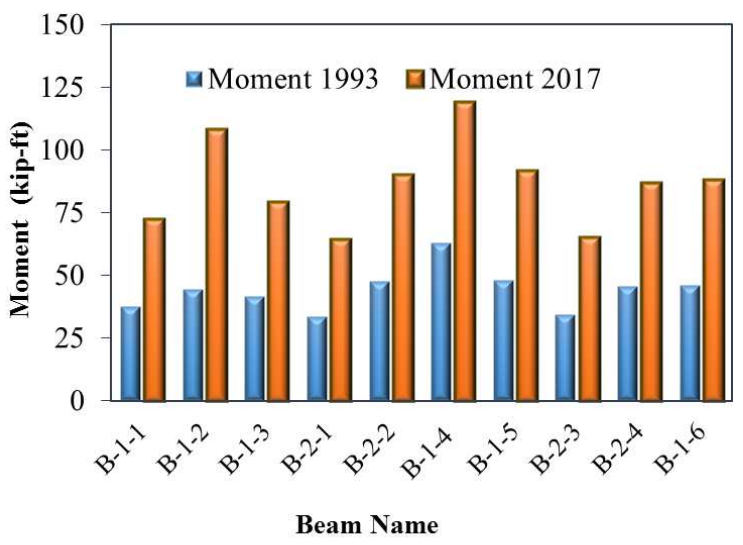

d)

Figure 4. Variations of moments in beam due to earthquake load; (a) Patuakhali, (b) Chadpur, (c) Rangpur (d) Moulovibazar.

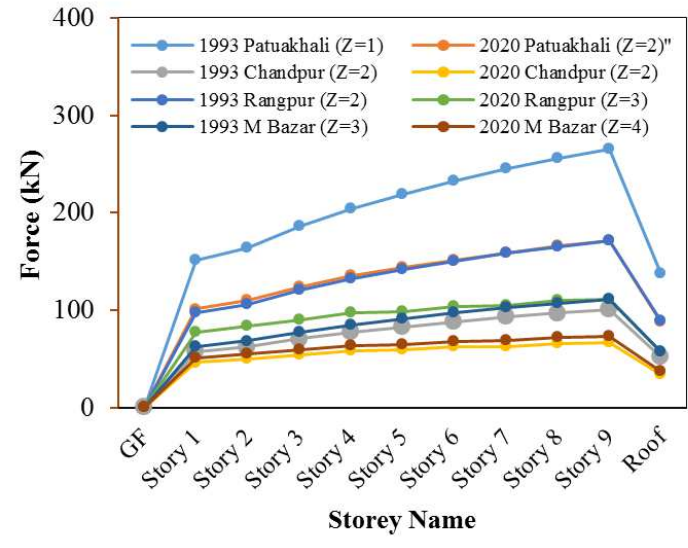

a)

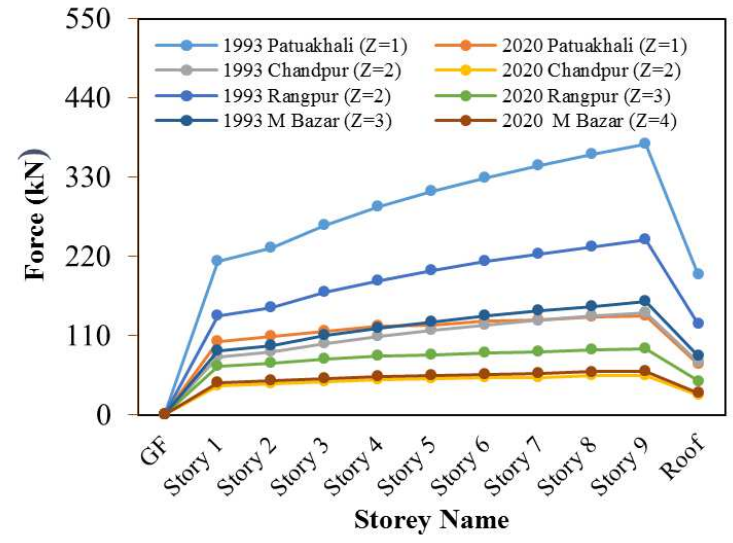

b)

Figure 5. Story drift due to wind load; (a) X-direction, (b) $Y$-direction. 


\subsection{Comparison of Wind Load Analysis}

For the case of wind load BNBC 2020 shows lower values as compared to BNBC 1993, although the basis wind speed is comparatively higher for BNBC 2020 (figure 4). There are two vital factors that are responsible for the case. Firstly, the gust coefficient $(\mathrm{G})$ value for the BNBC 2020 has been decreased to a great extent and it is almost half of the BNBC 1993. Secondly, pressure coefficient value has been split into two categories (windward side and leeward side) in BNBC 2020 and their summation value is much lower compared to

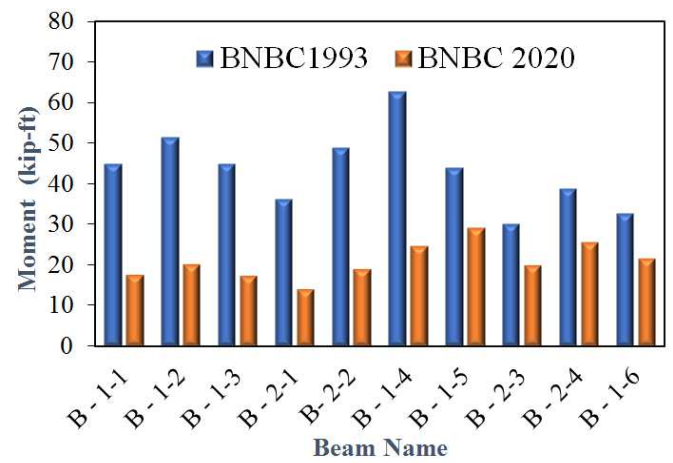

a)

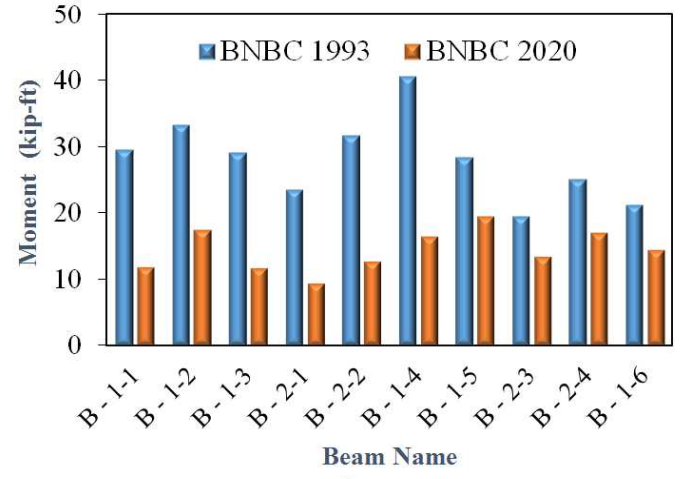

c)

Figure 6. Variations of moments in beam due to wind load; (a) Patuakhali, (b) Chadpur, (c) Rangpur (d) Moulovibazar. the value provided by BNBC 1993 .

Compared to earthquake load the story drift for wind load has a great similarity but here the story drift value is low for BNBC 2020 with respect to BNBC 1993 (figure 5). This is mainly due to the load value for two different codes. For the wind load cases the shape is like as parabola and this shape is clearly understanding for any district. As the wind force value is lower in BNBC 2020, the corresponding moment value is also lower for this code provisions. As a result, this indicates an economical design output (figure 6).

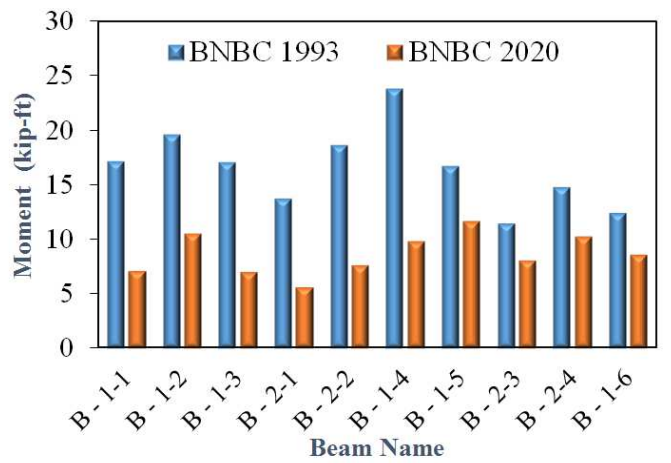

b)

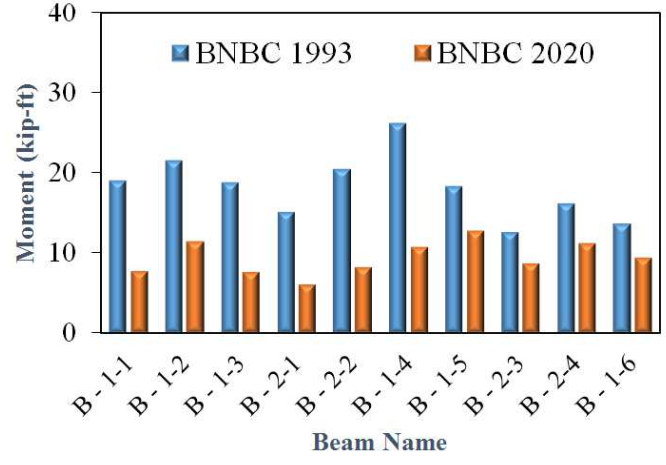

d)

\subsection{Comparisons of Other Cases}

Considering the change in the response modification coefficient value $(R)$ there is a good relationship with the $C / R$ ratio. The increase in $\mathrm{C} / \mathrm{R}$ and $C_{s} / \mathrm{R}$ decreases with the increase in height. From figure 7 , we find that the highest value is in 3rd story and lower value is on the top story for BNBC 2020 and for BNBC 1993 the highest value is on the first story and decreased with the increase in story number to the lowest value is on higher altitude. For BNBC 1993 the slope is almost straight from 3rd to 10th story but in case of BNBC 2020 the linear portion has started from 6th story to 10th story. The change in the ratio is highest in 3rd floor (146.43\%) and lowest in 1st floor (32.75\%).

A change in load combination for both Working Stress Design (WSD) and Ultimate Strength Design (USD) method has been noticed and it has a positive impact on the shear and moment developed on various parts of a structure for design purposes as well as foundation design also. Table 4 shows a view of the change in load combination as well as how much increased on which sector has been done in case of lateral load only. For dead load case $40 \%$ reduction has been done for WSD method but $14.3 \%$ increase has been counted for USD method in BNBC 2020 compared to BNBC 1993. For live load case $25 \%$ and $27.5 \%$ reduction has been proceeding for WSD and USD method respectively in BNBC 2020. The change in wind load or earthquake load is $25 \%$ to $47.5 \%$ increase for WSD method. On the same time for wind load case using USD method $23.1 \%$ and $25.5 \%$ increase has been considered for without live load and with live load consideration respectively. For earthquake load $43 \%$ and $40.25 \%$ reduction will have to count for without and with live load case. Other parameters like as pressure coefficient has a well changed value compared to BNBC 1993 as well as gust coefficient factor. Both the factor is significantly lowered in the updated version (BNBC 2020). Some significant changes have been introduced in the equations for earthquake and wind force calculations. 
Table 4. Comparison of load combinations for WSD and USD method in accordance with BNBC 1993 \& BNBC 2020.

\begin{tabular}{|c|c|c|c|c|c|}
\hline \multirow{2}{*}{$\begin{array}{l}\text { Design } \\
\text { Method }\end{array}$} & \multicolumn{2}{|l|}{ Code of Practice } & \multicolumn{3}{|c|}{ Change in Load w.r.to BNBC 1993} \\
\hline & BNBC 1993 & BNBC 2020 & DL (\%) & LL (\%) & Wind or EQ (\%) \\
\hline \multirow{4}{*}{ WSD } & $\mathrm{D}+\mathrm{W}$ & $0.6 \mathrm{D}+\mathrm{W}+\mathrm{H}$ & $40(\downarrow)$ & --- & --- \\
\hline & $\mathrm{D}+\mathrm{E}$ & $0.6 \mathrm{D}+0.7 \mathrm{E}+\mathrm{H}$ & $40(\downarrow)$ & --- & $30(\downarrow)$ \\
\hline & $\mathrm{D}+\mathrm{L}+\mathrm{W}$ & $\mathrm{D}+0.75 \mathrm{~W}+0.75\left(L_{r}\right.$ or $\left.\mathrm{R}\right)+0.75 \mathrm{~L}+\mathrm{H}+\mathrm{F}$ & -- & $25(\downarrow)$ & $25(\downarrow)$ \\
\hline & $\mathrm{D}+\mathrm{L}+\mathrm{E}$ & $\mathrm{D}+0.525 \mathrm{E}+0.75\left(L_{r}\right.$ or $\left.\mathrm{R}\right)+0.75 \mathrm{~L}+\mathrm{H}+\mathrm{F}$ & --- & $25(\downarrow)$ & $47.5(\downarrow)$ \\
\hline \multirow[t]{2}{*}{ USD } & $\begin{array}{l}0.9 \mathrm{D}+1.3 \mathrm{~W} \\
0.9 \mathrm{D}+1.43 \mathrm{E} \\
1.05 \mathrm{D}+1.275 \mathrm{~L}+1.275(\mathrm{H} \text { or } \mathrm{F})+1.275 \mathrm{~W}\end{array}$ & $\begin{array}{l}0.9 \mathrm{D}+1.6 \mathrm{~W}+1.6 \mathrm{H} \\
0.9 \mathrm{D}+1.0 \mathrm{E}+1.6 \mathrm{H} \\
1.2 \mathrm{D}+1.0 \mathrm{~L}+1.6 \mathrm{~W}+0.5\left(L_{r} \text { or } \mathrm{R}\right)\end{array}$ & $\begin{array}{l}--- \\
--- \\
14.3(\uparrow)\end{array}$ & $\begin{array}{l}--- \\
--- \\
27.5(\downarrow)\end{array}$ & $\begin{array}{l}23.1(\uparrow) \\
43(\downarrow) \\
25.5(\uparrow)\end{array}$ \\
\hline & $1.05 \mathrm{D}+1.275 \mathrm{~L}+1.275(\mathrm{H}$ or $\mathrm{F})+1.4025 \mathrm{E}$ & $1.2 \mathrm{D}+1.0 \mathrm{~L}+1.0 \mathrm{E}$ & $14.3(\uparrow)$ & $27.5(\downarrow)$ & $40.25(\downarrow)$ \\
\hline
\end{tabular}

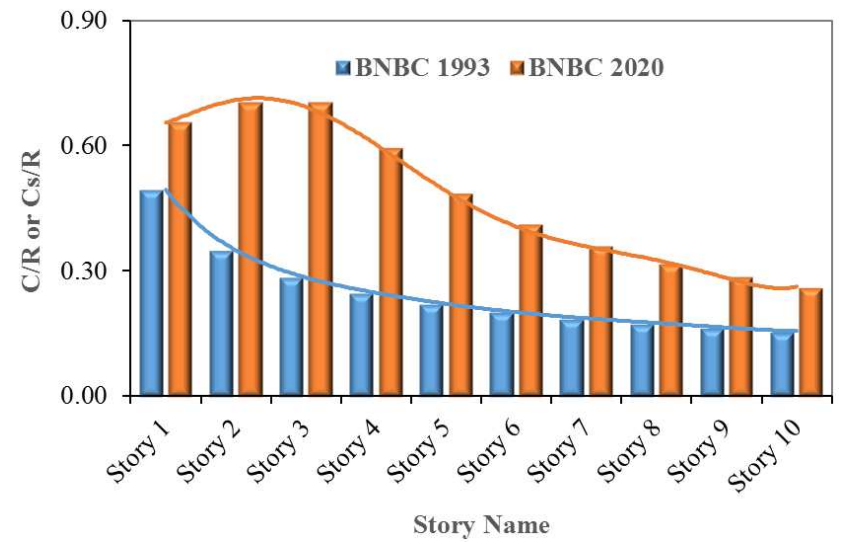

Figure 7. $C / R$ or $C_{S} / R$ ratio w.r.to story number.

\section{Conclusion}

The latest base shear values among both codes in this article is indicated by BNBC 1993. While Bangladesh lies on strong and susceptible earthquake zone, the question arises that the structures designed in accordance with the BNBC 1993 need to be retrofitted or refurbished! This conflict of BNBC 1993 may be dangerous when developed countries move towards more conservative design for the property owners following this code of practice to construct their project. BNBC 2020 will be a more cautious approach to Bangladesh's tectonic design sectors. Consequently, this improvement in the safety margin against the BNBC 2020 for earthquake with higher base shear values is significant. But the need for significantly greater reinforcement of low rise structures which might affect the design of the construction in Bangladesh for BNBC 2020. Throughout the study we found some parameters those are responsible for higher seismic base shear in BNBC like as increase in seismic zone coefficient (Z), Response Modification Coefficient (R) reduction, consider of upto $3 \mathrm{kN} / \mathrm{m}^{2}$ with a minimum of $25 \%$ live load as a fixed seismic dead weight (W) for all cases, increased normalized response spectrum acceleration $\left(C_{s}\right)$. In 1993 BNBC does not adequately describe the seismic design base. The seismic design criterion is 0.67 times BNBC 2020's peak earthquake. For Seismic loading, BNBC 1993 uses force multiplier 1.4025. This indicates that due to ambiguity of load, the seismic load is boosted to 40 percent, despite the peak quake is taken into account and the multiplier is thus not necessary. Besides, the base shear, the story drift is found to be much higher for
BNBC 2020 than BNBC 1993. Despite modification of the code, BNBC 2020 still proposes lower base shear values than the other codes such as Indian and American code. In this respect further investigations must be performed.

The vertical dispersion of earthquake force on the BNBC 2020 differs from that on the BNBC 1993. The BNBC 2020 specifies a straight dispersion and a parabolic dispersion for buildings with $\mathrm{T}$ less than $0.5 \mathrm{sec}$ and $\mathrm{T}$ greater than $2.5 \mathrm{sec}$ that range from 0 at the baseline to a peak at the apex. During mid-term period, a linear interpolation among a linear dispersion and a parabola dispersion or even a more restrictive parabola distribution could be used. For configuration with $\mathrm{T}$ is less than $0.7 \mathrm{sec}$, the BNBC 1993 uses a linear dispersion with zero value. The design base shear part $(0,07 \mathrm{TV} \leq 0.25 \mathrm{~V})$ is focused for longer period buildings at the apex, the rest of the base shear being spread uniformly for short term buildings.

A single experimental equation was employed prior BNBC 1993 in order to identify wind thrust that did not take into account the influence of the adjacent item and the elevation of wind thrust on the structures. In the BNBC 1993 establishment of exposure classifications (A, B \& C) and gust coefficient (G) was solved this limitation. In BNBC 2020 wind allowance, the impact of adjacent obstacles and structural heights has been significantly improved. As a result, according to BNBC 2020 wind load is found the be significantly lower for exposure category A compared to BNBC 1993. Two new terms topographic factor $\left(K_{z t}\right)$ and directional factor $\left(K_{d}\right)$ has been introduced in BNBC 2020. For wind load the maximum story drift with respect to story number is less in BNBC 2020 compared to BNBC 1993. The remarkable decrease in two important parameters, gust factor $(G)$ and wind pressure coefficient is responsible for this reduction in wind force.

Integrating the findings obtained from multiple indicators, it can be concluded that when subjected to seismic loading, structural designs as per BNBC 2020 were more efficient than wind force. There is significant reduction in dead load, live load, wind and earthquake load in design load combination. That's why the design is economical in BNBC 2020 compared to BNBC 1993 for both WSD and USD method although there is $14.3 \%$ increase in dead load and around $25 \%$ increase in wind load case has been suggested for USD method in BNBC 2020. In spite of increase in earthquake load or reduction of wind force a reduction on the construction cost is anticipated due to change in load combinations. 


\section{Conflict of Interest Statement}

All the authors do not have any possible conflicts of interest.

\section{References}

[1] S. Mahmoud, "In-Plane Shear-Wall Configuration Effects on the Seismic Performance of Symmetrical Multistory Reinforced-Concrete Buildings," Int. J. Civ. Eng., vol. 8, 2021.

[2] A. Brencich and M. Gnecco, "Failure Case Studies in Structural Engineering Courses and Professional Practice," Arab. J. Sci. Eng., vol. 37, no. 8, pp. 2113-2126, 2012.

[3] A. Tuken and N. A. Siddiqui, "Assessment of Shear Wall Quantity in Seismic-Resistant Design of Reinforced Concrete Buildings," Arab. J. Sci. Eng., vol. 38, no. 10, pp. 2639-2648, 2013.

[4] S. Das Gupta, K. H. Kanak, R. Islam, and F. Khan, "Structural Analysis of a High-Rise Building under Strong Winds Using ETABS," vol. 3, no. 1, pp. 1-9, 2020.

[5] T. M. Al-Hussaini, T. R. Hossain, and M. Nayeem Al-Noman, "Proposed changes to the geotechnical earthquake engineering provisions of the Bangladesh national building code," Geotech. Eng., vol. 43, no. 2, pp. 1-7, 2012.

[6] M. S. Bari and T. Das, "A Comparative Study on Seismic Analysis of Bangladesh National Building Code (BNBC) with Other Building Codes," J. Inst. Eng. Ser. A, vol. 94, no. 3, pp. 131-137, 2013.

[7] S. Islam, "Analysis on the Structural Systems for Drift Control of Tall Buildings due to Wind Load: Critical Investigation on Building Heights," J. Sci. Technol., vol. 5, no. 1, pp. 1-19, 2014.
[8] V. Varalakshmi, G. S. Kumar, and R. S. Sarma, "Analysis and Design of $\mathrm{G}+5$ Residential Building ABSTRACT :," Int. Res. J. Eng. Technol., vol. 4, no. 6, pp. 73-77, 2017.

[9] F. S. Imam, S. Tahsin, and A. Hassan, "Comparative Study On Lateral Load Analysis By BNBC - 1993 And Proposed BNBC - 2012," Int. J. Sci. Technol. Res., vol. 3, no. 11, pp. 57-61, 2014.

[10] A. Akter and S. Akter, "Wind velocity for Dhaka Divition Wind velocity in Mymensing Division," no. February, pp. 112, 2018.

[11] S. Zakir, A. Akther, and K. M. Amanat, "A Comparative Study of BNBC 1993 and 2017 Provisions for the Design of Multistoried Steel Buildings in High Wind and High Seismic Zone A Comparative Study of BNBC 1993 and 2017 Provisions FOR the Design of Multistoried Steel Buildings in High Wind and Hig,” no. January, pp. 4-9, 2019.

[12] R. M. Faysal, "Comparison of Wind Load among BNBC and other Codes in different type of areas," Basha Res. Corp., vol. 03, no. 03, 2014.

[13] S. Z. Sarothi, M. S. Sakib, M. A. Hasan, A. Akhter, T. Rabbi, and D. K. M. Amanat, "COMPARATIVE ANALYSIS OF RC FRAME STRUCTURES FOLLOWING BNBC 1993 AND 2017 VERSIONS OF CODE FOR HIGH SEISMIC AND HIGH WIND ZONE Modeling and Analysis," pp. 84-88, 2019.

[14] Housing and Building Research Institute, Bangladesh National Building Code 1993. Bangladesh, 1993.

[15] BNBC, "Bangladesh National Building Code (BNBC) 2020," House Build. Res. Inst., no. 2, 2020.

[16] F. Atique and Z. Wadud, "a Comparison of Bnbc-93 With Other Building Codes With Respect To Earthquake and Wind Analysis," no. December 2001, pp. 0-5, 2003. 